\title{
Economic Benefits and Costs Associated With Target Vaccinations
}

\author{
Edward P. Armstrong, PharmD, FASHP
}

\begin{abstract}
BACKGROUND: As a therapeutic class, vaccines are generally considered to be the health care intervention that provides the best value. In the pharmacoeconomic study of vaccines, it is common for researchers to conduct their analyses from a societal perspective, including direct medical costs as well as indirect costs.

OBJECTIVE: To discuss the data elements of pharmacoeconomic analyses of vaccines and review recently published analyses of emerging vaccines.

SUMMARY: Myriad pharmacoeconomic analyses of vaccines currently in use have been conducted with varying results. A number of products, such as the diphtheria-tetanus-acellular pertussis, hepatitis $B$, and varicella vaccines, have been shown to be cost-effective from a societal perspective. Yet, other products, such as the pneumococcal conjugate vaccine, have demonstrated less benefit than the cost of their respective vaccination programs. In general, these analyses can be used as a starting point to frame the benefits of specific vaccines in managed care with a balanced view of the necessary societal perspectives. To date, 6 pharmacoeconomic models have evaluated vaccination against human papillomavirus, with all demonstrating some cost benefit when the vaccine was used in female patients who fell within the indicated age range.

CONCLUSIONS: In general, as a therapeutic class, vaccines are extremely cost-effective agents. In addition, they are one of the few public health interventions that may directly lower medical costs. In conducting pharmacoeconomic analyses for agents in this class, researchers must consider costs incurred at both the health system and societal levels, as well as cost savings realized through the prevention of disease.
\end{abstract}

KEYWORDS: Pharmacoeconomic, Cost, Cost-effective, Vaccine, HPV, Hepatitis

J Manag Care Pharm. 2007;13(7)(suppl S-b):S12-S15

Copyright $\odot$ 2007, Academy of Managed Care Pharmacy. All rights reserved.

\section{Author}

EDWARD P. ARMSTRONG, PharmD, is a professor, pharmacy practice and science and pharmaceutical services, College of PharmacyDrachman Hall, University of Arizona, Tucson.

AUTHOR CORRESPONDENCE: Edward P. Armstrong, PharmD, Professor, College of Pharmacy-Drachman Hall, University of Arizona, Tucson, AZ 85721. Tel: (520) 626-5764; Fax:(520) 626-7355;

E-mail:armstrong@pharmacy.arizona.edu
A $s$ a therapeutic class, vaccines are generally considered to be the health care intervention that provides the best value. ${ }^{1}$ Vaccine products are known to have provided more benefit to society than expense, and they have been estimated to save society more than $\$ 5$ for each dollar spent on most routine pediatric vaccinations. ${ }^{2}$ Two vaccines that have had a remarkable impact on eliminating diseases are the polio and smallpox vaccines. ${ }^{3}$ Other serious diseases that have been prevented include diphtheria, tetanus, whooping cough, invasive Haemophilus influenzae type b disease, rubella, mumps, and measles. In light of the success of vaccines to date, high immunization rates remain the key for society to continue to benefit from these preventive treatments.

Vaccines have had an impressive impact on decreasing disease morbidity within the United States, as evidenced by the Centers for Disease Control and Prevention's annual morbidity estimates for a range of diseases both before the introduction of vaccines and their current estimates (Table 1). ${ }^{4,5}$ It is noted that the annual burden for these 9 diseases has either approached or exceeded a $90 \%$ reduction through the use of vaccines. ${ }^{4,5}$

In addition to the impact of vaccines within the United States, vaccination programs have also had a worldwide effect in reducing the number of deaths from specific diseases. ${ }^{1}$ Table 2 highlights that nearly 3 million lives have been saved globally from vaccine-preventable diseases because of increased vaccine coverage. ${ }^{1}$ Ehreth $^{1}$ has compiled data demonstrating the following:

- Savings in direct medical costs due to the eradication of smallpox in 1977 exceed $\$ 300$ million dollars per year.

- One case of measles is estimated to cost 23 times the amount spent to vaccinate 1 child against measles.

- For every dollar spent on measles-mumps-rubella vaccine, more than $\$ 21$ is saved in direct medical costs.

- For every dollar spent on diphtheria-tetanus-acellular pertussis vaccine, more than $\$ 24$ is saved.

- For every dollar spent on $H$. influenzae type b vaccine, more than $\$ 2$ is saved.

\section{Data Elements of}

\section{Pharmacoeconomic Analyses of Vaccines}

For many pharmacoeconomic analyses, the study perspective has often been that of a health system, and the primary cost data collected are direct medical costs (e.g., medication costs, cost of hospitalizations for severe illness, costs associated with the management of adverse events). However, in pharmacoeconomic studies of vaccines, it is common for researchers to conduct their analyses from a societal perspective, including direct medical costs as well as indirect costs. Indirect costs include considerations for cost savings resulting from the preventive elements of vaccines, such as fewer missed work days. ${ }^{6}$ For 


\begin{tabular}{l|c|c|c}
\hline \multicolumn{1}{c|}{ TABLE 1) } & $\begin{array}{c}\text { Comparison of Morbidity Before } \\
\text { and After Introduction of Vaccines }\end{array}$ \\
\hline & $\begin{array}{c}\text { Annual Morbidity } \\
\text { Before Introduction }\end{array}$ & $\begin{array}{c}\text { Current Annual } \\
\text { Morbidity }\end{array}$ & $\begin{array}{c}\% \\
\text { Decrease }\end{array}$ \\
\hline Disease & 175,885 & 0 & 99.9 \\
\hline Diphtheria & 503,282 & 37 & 99.9 \\
\hline Measles & 152,209 & 236 & 99.8 \\
\hline Mumps & 147,271 & 18,957 & 87.1 \\
\hline Pertussis & 16,316 & 0 & 100 \\
\hline Polio (paralytic) & 47,745 & 12 & 99.9 \\
\hline Rubella & 823 & 0 & 100 \\
\hline Congenital rubella & 1,314 & 26 & 98.0 \\
syndrome & 20,000 & 172 & 99.1 \\
\hline Tetanus & & & \\
\hline H. influenza & & & \\
\hline
\end{tabular}

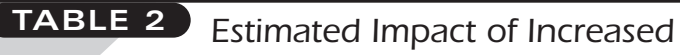 Vaccine Coverage on Vaccine-Preventable Diseases ${ }^{1}$}

\begin{tabular}{l|c}
\hline Disease & Annual Deaths Prevented \\
\hline Hepatitis B & 900,000 \\
\hline Measles & 888,000 \\
\hline Hemophilus influenza b & 400,000 \\
\hline Pertussis & 346,000 \\
\hline Neonatal tetanus & 215,000 \\
\hline Tetanus & 195,000 \\
\hline Yellow fever & 30,000 \\
\hline Diphtheria & 5,000 \\
\hline Poliomyelitis & 720 \\
\hline Total & $2,979,720$ \\
\hline
\end{tabular}

example, the calculated vaccine benefit when considering indirect costs may include the savings realized when parents do not need to take time off from work because the administered vaccine prevented pediatric infections from occurring. Similarly, because vaccines may prevent death, another benefit considered in pharmacoeconomic analyses of vaccines is that they allow children to mature into productive members of society. In these analyses, vaccine intervention costs may be compared against reduced disease treatment costs, work loss costs, and patient mortality costs. Including indirect costs in pharmacoeconomic analyses provides the broadest assessment of vaccines and improves their cost-effectiveness because they include financial benefits that occur outside of health systems.

\section{Review of Pharmacoeconomic Analyses of Vaccines}

Using the aforementioned direct and indirect cost considerations, myriad pharmacoeconomic analyses of vaccines currently in use have been conducted with varying results. In general, these analyses can be used as a starting point to frame the benefits of specific vaccines in managed care with a balanced view of necessary societal perspectives. The following review of select published pharmacoeconomic analyses of vaccines demonstrates the value of conducting these analyses in managed care when all relevant criteria are considered.

The diphtheria-tetanus-acellular pertussis vaccine has been shown to be cost-effective from both the societal and health system perspectives. ${ }^{7}$ The hepatitis B vaccine has been shown to be cost-effective from a societal perspective, costing $\$ 1,522$ per year of life gained when administered to infants from a health system perspective. ${ }^{8}$ The varicella vaccine has been shown to be cost-effective from a societal perspective and to cost $\$ 2,500$ per year of life gained from a health system perspective. ${ }^{9}$ However, the pneumococcal conjugate vaccine has been shown to cost $\$ 80,000$ per year of life gained from a societal perspective (i.e., the benefit was less than the cost of the vaccination program). ${ }^{10}$ The authors noted that although the pneumococcal conjugate vaccine can be a useful and important vaccine, it provides less value economically at the manufacturer's list price.

One analysis compared the cost-benefit and cost-effectiveness of varicella, hepatitis A, and pneumococcal conjugate vaccines. ${ }^{11}$ The authors reviewed U.S. cost-effectiveness studies and assessed each vaccine from both a health system and societal perspective. From a societal perspective, the varicella vaccine had a cost-benefit ratio between $\$ 4.76$ and $\$ 5.61$ for each dollar spent. From a societal perspective, the hepatitis A vaccine had a cost-benefit ratio of $\$ 1.96$ for each dollar spent. However, from a societal perspective, the pneumococcal conjugate vaccine had a benefit of $\$ 0.68$ for each dollar spent (i.e., the financial benefit was less than the cost of the vaccination program). The authors noted that the pneumococcal conjugate vaccine would cost twice the amount of the varicella and hepatitis $\mathrm{A}$ vaccines combined and would be less cost-effective than the other vaccines.

Pharmacoeconomic analyses can also be applied to evaluate the use of different forms of the same vaccine (e.g., inactivated vs. live attenuated) compared with simply evaluating use versus nonuse. One study created cost-benefit and cost-effectiveness models to compare the introduction of inactivated poliovirus vaccine to reduce vaccine-associated paralytic poliomyelitis, an uncommon complication that is associated with the live-attenuated oral poliovirus vaccine. ${ }^{12}$ Use of the inactivated poliovirus vaccine was estimated to cost at least $\$ 3$ million for each case of vaccine-associated paralytic poliomyelitis that was avoided.

In addition to assessing the value of specific vaccines in managed care, pharmacoeconomic analyses can also be used to evaluate different strategies for vaccination. One study created a decision-analytic model using direct medical costs to 


\begin{tabular}{|c|c|c|c|c|}
\hline Outcome* & $\begin{array}{c}\text { HPV } \\
\text { Vaccination }\end{array}$ & $\begin{array}{c}\text { No HPV } \\
\text { Vaccination }\end{array}$ & $\begin{array}{c}\text { Lifetime } \\
\text { Cases } \\
\text { Averted }\end{array}$ & $\begin{array}{c}\text { No. Needed } \\
\text { to Vaccinate } \\
\text { to Prevent } \\
1 \text { Case }\end{array}$ \\
\hline HPV & $1,460,699$ & $1,684,954$ & 224,255 & 9 \\
\hline SIL & 417,549 & 530,259 & 112,710 & 18 \\
\hline $\begin{array}{l}\text { Cervical } \\
\text { cancer }\end{array}$ & 13,374 & 16,690 & 3,316 & 600 \\
\hline $\begin{array}{l}\text { Cervical } \\
\text { cancer deaths }\end{array}$ & 5,121 & 6,461 & 1,340 & 1,484 \\
\hline
\end{tabular}

* Assumes program that successfully administers a vaccine against high-risk HPV to the current U.S. cohort of 12-year-old girls.

$H P V=$ human papillomavirus; $S I L=$ squamous intraepithelial lesions

\begin{tabular}{l|c|c}
\hline TABLE 4 & $\begin{array}{l}\text { Projected Cost-Effectiveness of } \\
\text { Human Papillomavirus Vaccination }\end{array}$ \\
\hline Outcome* & $\begin{array}{c}\text { No HPV } \\
\text { Vaccination }\end{array}$ & $\begin{array}{c}\text { HPV } \\
\text { Vaccination }\end{array}$ \\
\hline Cost, \$ & 39,682 & 39,928 \\
\hline Incremental cost, \$ & 28.785 & 246 \\
\hline Life expectancy, years & & 28.793 \\
\hline Incremental life expectancy, days & 27.72 & 27.731 \\
\hline $\begin{array}{l}\text { Quality-adjusted life expectancy, years } \\
\text { Incremental quality-adjusted life } \\
\text { expectancy, days }\end{array}$ & & 4 \\
\hline
\end{tabular}

Incremental cost-effectiveness $\$$ /life-year

\begin{tabular}{l|l|l}
\hline \$/life-year gained & & 32,066 \\
\hline \$/quality-adjusted life-year gained & & 22,755 \\
\hline
\end{tabular}

* Assumes program that successfully administers a vaccine against high-risk HPV to the current U.S. cohort of 12-year-old girls.

$\mathrm{HPV}=$ human papillomavirus.

compare 2 treatment strategies for patients with hepatitis $C$ to be vaccinated against both hepatitis $A$ and hepatitis $B .{ }^{13}$ The authors determined that a universal strategy of immunizing patients suffering from hepatitis C against both hepatitis A and hepatitis B was more effective, but more costly, than first testing patients for immunity and then selective immunization. However, the incremental cost-effectiveness ratio was only $\$ 154$ for the universal immunization strategy, indicating that this was a very good value and therefore recommended by the authors.

In assessing vaccination strategies, another study evaluated whether it was cost-beneficial, from a societal perspective, to routinely vaccinate incoming first-year college students living in dormitories. ${ }^{14}$ The authors determined that the cost of the needed vaccination program would far exceed the benefits of preventing meningococcal disease. It was estimated that the net cost per meningococcal case averted ranged from \$0.6 million to $\$ 1.9$ million and from $\$ 7$ million to $\$ 20$ million per death averted. The authors did not recommend routine vaccination of first-year U.S. college students living in dormitories because of the low incidence of disease and the high cost of the vaccination program.

One vaccine under particular scrutiny in managed care is the recently introduced human papillomavirus (HPV) vaccine. To date, 6 pharmacoeconomic models have evaluated vaccination against HPV. ${ }^{15}$ One model estimated the impact of vaccinating all 12-year-old girls in the United States with a vaccine active against HPV-16 and HPV- $18 .{ }^{16}$ The authors estimated the number of lifetime cases of cervical squamous intraepithelial lesions and cases of cervical cancer that could be prevented with such an immunization program. Table 3 summarizes the estimated clinical benefits of HPV vaccination. The authors estimated that 18 girls would need to be vaccinated to prevent 1 case of cervical squamous intraepithelial lesion and 600 girls would need to be vaccinated to prevent 1 case of cervical cancer. ${ }^{16}$ Table 4 summarizes the cost and cost-effectiveness results from the analysis. The authors estimated the cost per quality-adjusted lifeyear gained to be $\$ 22,755$ for the cohort of 12 -year-old girls. ${ }^{16}$

The authors then revised their model to include a range of vaccine efficacies as well as population penetration of HPV and compared the vaccination of only 12-year-old girls versus the vaccination of both girls and boys. ${ }^{17}$ They estimated that the number of expected lifetime cases of cervical cancer related to HPV-16 or HPV-18 would decrease by $95.4 \%$ and that vaccination would add an average of 6.1 quality-adjusted lifeyears per woman. The cost-effectiveness ratio of the HPV vaccine was estimated to be $\$ 14,583$ per quality-adjusted lifeyears gained. When the authors examined the vaccination of both girls and boys, it was estimated that cervical cancer cases would drop by $98.8 \%$ compared with no vaccination program and that an incremental 0.21 quality-adjusted life-year would be added per woman compared with only the vaccination of girls. However, the incremental cost-effectiveness ratio of $\$ 442,039$ per quality-adjusted life-years gained compared with only the vaccination of girls was substantial. Because this incremental ratio was so large, the authors did not recommend the vaccination of boys. ${ }^{17}$

\section{Conclusions}

Vaccinations are one of the most significant public health interventions to emerge in the past century. In conducting pharmacoeconomic analyses for agents in this class, researchers must consider costs incurred at both the health system and societal levels as well as cost savings realized through the prevention 
of disease. Overall, as a therapeutic class, vaccines are extremely cost-effective agents. In addition, vaccines are one of the few public health interventions that may directly lower medical costs. The cost of many vaccinations is less than the cost needed to treat preventable diseases. Emerging vaccines, including those targeting HPV, also appear to be cost-effective interventions.

Despite the clinical success and cost-effectiveness of many vaccination programs, it is very important to remain vigilant in achieving high vaccination rates, especially for children. Even though some previous theoretical concerns (e.g., possible autismcausedfromthemeasles-mumps-rubellavaccine) havebeen refuted, improved vaccination rates should still be sought. ${ }^{18}$ If vaccination rates drop, the United States would be susceptible to infection from countries where specific vaccines were either unavailable or underused.

\section{DISCLOSURES}

This article is based on a presentation given by the author at a symposium, "The Value of Preventive Medicine: A Look at Vaccine Management," held Apri 11, 2007, at the Academy of Managed Care Pharmacy's 19th Annual Meeting and Showcase in San Diego, California. The symposium was supported by an educational grant from GlaxoSmithKline. The author discloses that he has received an honorarium for participation in the presentation and in this supplement. He discloses no potential bias or conflict of interest relating to this article.

\section{REFERENCES}

1. Ehreth J. The global value of vaccination. Vaccine. 2003;21:596-600.

2. Gardner P, Pickering LK, Orenstein WA, Gershon AA, Nichol KL. Infectious Diseases Society of America. Guidelines for quality standards for immunization. Clin Infect Dis. 2002;35:503-11.

3. Abramson JS, Pickering LK. US immunization policy. JAMA. 2002;287: 505-09.

4. Centers for Disease Control and Prevention. Ten great public health achievements-United States, 1900-1999. MMWR Morb Mortal Wkly Rep. 1999;48: 242-64.
5. Centers for Disease Control and Prevention. Notifiable diseases/deaths in selected cities weekly information. MMWR Morb Mortal Wkly Rep. 2005;53: 1213-21.

6. Meltzer MI. Introduction to health economics for physicians. Lancet. 2001;358:993-98

7. Ekwuene DU, Strebel PM, Hadler SC, Meltzer MI, Allen JW, Livengood JR. Economic evaluation of use of diphtheria, tetanus, and acellular pertussis vaccine or diphtheria, tetanus, and whole-cell pertussis vaccine in the United States, 1997. Arch Pediatr Adolesc Med. 2000;154:797-803.

8. Margolis HS, Coleman PJ, Brown RE, Mast EE, Sheingold SH, Arevalo JA Prevention of hepatitis B virus transmission by immunization. An economic analysis of current recommendations. JAMA. 1995;274:1201-08.

9. Lieu TA, Cochi SL, Black SB, et al. Cost-effectiveness of a routine varicella vaccination program for US children JAMA. 1994;271:375-81.

10. Lieu TA, Ray GT, Black SB, et al. Projected cost-effectiveness of pneumococcal conjugate vaccination of healthy infants and young children. JAMA. 2000;283:1460-68

11. Jacobs RJ, Meyerhoff AS. Comparative cost effectiveness of varicella, hepatitis A, and pneumococcal conjugate vaccines. Prev Med. 2001;33:639-45.

12. Miller MA, Sutter RW, Strebel PM, Hadler SC. Cost-effectiveness of incorporating inactivated poliovirus vaccine into the routine childhood immunization schedule. JAMA. 1996;276:967-71.

13. Jakiche R, Borrego ME, Raisch DW, Gupchup GV, Pai MA, Jakiche A. The cost-effectiveness of two strategies for vaccinating US veterans with hepatitis C virus infection against hepatitis A and hepatitis B viruses. Am J Med Sci. 2007;333:26-34.

14. Scott II RD, Meltzer MI, Erickson LJ, De Wals P, Rosenstein NE. Vaccinating first-year college students living in dormitories for meningococcal disease. An economic analysis. Am J Prev Med. 2002;23:98-105.

15. Dasbach EJ, Elbasha EH, Insinga RP. Mathematical models for predicting the epidemiologic and economic impact of vaccination against human papillomavirus infection and disease. Epidemiol Rev. 2006;28:88-100.

16. Sanders GD, Taira AV. Cost effectiveness of a potential vaccine for human papillomavirus. Emerg Infect Dis. 2003;9:37-48.

17. Taira AV, Neukermans CP, Sanders GD. Evaluating human papillomavirus vaccination programs. Emerg Infect Dis. 2004;10:1915-23. Abramon JS, Pickering LK. US immunization policy. JAMA. 2002;287:505-09. 